\title{
RANCANGAN MESIN PEMBELAH BUAH PINANG DENGAN DUA MATA POTONG
}

\author{
Rodika1, Tuparjono $^{2}$, Budi Otomo ${ }^{3}$, Riska Ade Febryani ${ }^{4}$ \\ 1,2,3,4 Jurusan Teknik Mesin, Politeknik Manufaktur Negeri Bangka Belitung \\ Kawasan Industri Airkantung Sungailiat, \\ Telp.0717-93586, Fax.0717-93585, r_rodika@ymail.com
}

\begin{abstract}
Betel nut palm plant is one of the many benefits and efficacy, especially seeds. Areca nuts are widely used as the main raw material in the process of making drugs, cosmetics, slimming, snacks, sweets, and coffee. Betel nut processing into betel nut is still constrained by the tool is still modest, are still using wood beams repose knife to split betel nut into two parts. To overcome these problems needed betel nut splitter machine with a capacity of $250 \mathrm{~kg} / \mathrm{h}$. This engine design is expected to help farmers during the process of betel nut processing into dried betel nut. The working principle of betel nut splitter machine originated from an electric motor that produces rotation is forwarded to the reducer and to the cutting blade associated with two gears. Betel nut is inserted through the insertion funnel towards the rotor has 4 channels / trench, and rotor spinning and crashing betel nut rotating blades reversed so the rotor besides betel nut split into two parts. Shaft rotation speed at the eye-piece and carrier rotor shaft is $9.32 \mathrm{rpm}$, the rotation speed is obtained from the ratio gearbox and pulley on the engine splitter ratio. With the machine is expected to help farmers to cultivate betel nut, so the work is lighter, faster and may prevent accidents. Shaft rotation speed at the eye-piece and carrier rotor shaft is $9.32 \mathrm{rpm}$, the rotation speed is obtained from the ratio gearbox and pulley on the engine splitter ratio. With the machine is expected to help farmers to cultivate betel nut, so the work is lighter, faster and may prevent accidents. Shaft rotation speed at the eye-piece and carrier rotor shaft is $9.32 \mathrm{rpm}$, the rotation speed is obtained from the ratio gearbox and pulley on the engine splitter ratio. With the machine is expected to help farmers to cultivate betel nut, so the work is lighter, faster and may prevent accidents.
\end{abstract}

Keywords: betel nut, betel nut, splitter, the speed of rotation

\begin{abstract}
Abstrak
Buah pinang merupakan salah satu tumbuhan palma yang banyak manfaat dan khasiat, terutama bijinya. Biji pinang banyak dimanfaatkan sebagai bahan baku utama dalam proses pembuatan obat, kosmetik, pelangsing, makanan ringan, permen, dan kopi. Pengolahan buah pinang menjadi biji pinang saat ini masih terkendala dengan alat yang masih sederhana, yaitu masih menggunakan pisau yang beralaskan kayu balok untuk membelah buah pinang menjadi dua bagian. Untuk mengatasi permasalah tersebut dibutuhkan mesin pembelah buah pinang dengan kapasitas $250 \mathrm{~kg} / \mathrm{jam}$. Rancangan mesin ini diharapkan dapat membantu petani pada saat proses pengolahan buah pinang menjadi biji pinang kering. Prinsip kerja mesin pembelah buah pinang ini berawal dari motor listrik yang menghasilkan putaran yang diteruskan pada reducer lalu ke pisau pemotong yang dihubungkan dengan dua roda gigi. Buah pinang dimasukkan melalui corong pemasukkan menuju rotor yang memiliki 4 celah/parit, lalu rotor berputar dan buah pinang menabrak pisau yang berputar berbalik arah disamping rotor sehingga buah pinang terbelah menjadi dua bagian. Kecepatan putaran poros pada mata potong dan poros rotor pembawa adalah 9,32 rpm, kecepatan putaran ini didapat dari ratio gearbox dan ratio pulley pada mesin pembelah. Dengan adanya mesin ini diharapkan dapat membantu petani dalam mengolah buah pinang, sehingga pekerjaan lebih ringan, cepat dan dapat mencegah terjadinya kecelakaan.
\end{abstract}

Kata kunci: buah pinang, biji pinang, pembelah, kecepatan putaran

\section{PENDAHULUAN}

Pinang (Areca catechu L) merupakan salah satu tumbuhan palma. Tumbuhan ini tersebar dari Afrika Timur, Semenanjung Arab, Tropikal Asia, Indonesia, dan Papua New Guinea.[1] Buah pinang merupakan tanaman yang banyak manfaat dan khasiat, terutama bijinya. Biji pinang banyak dimanfatkan 
sebagai bahan baku utama dalam proses pembuatan obat, kosmetik, pelangsing, makanan ringan, permen, dan kopi. [2]

Proses pengolahan buah pinang menjadi biji pinang kering ini dapat dilakukan dengan cara membelah buah pinang dengan alat pemotong berupa pisau yang dikombinasikan dengan kayu sebagai landasan pisau. Setelah di belah buah dijemur sampai kering di atas karung atau tikar selama tiga hari. Proses pembelahan buah pinang yang di lakukan olah masyarakat kebanyakan masih menggunakan cara manual, sehingga beresiko terjadi kecelakaan.

Dari permasalahan tersebut dibutuhkan rancangan alat pemotong buah pinang dengan kapasitas $250 \mathrm{~kg} / \mathrm{jam}$ dan proses pemotongannya dapat dilakukan dengan lebih cepat dan aman. Rancangan mesin pembelah buah pinang ini memiliki dua sisi mata potong dan dua rotor pembawa. Prinsip kerja mesin pembelah buah pinang ini berawal dari motor listrik yang menghasilkan putaran yang diteruskan pada reducer lalu ke pisau pemotong yang dihubungkan dengan dua roda gigi. Buah pinang dimasukkan melalui corong pemasukkan menuju rotor yang memiliki 4 celah/parit, lalu rotor berputar dan buah pinang menabrak pisau yang berputar berbalik arah disamping rotor sehingga buah pinang terbelah menjadi dua bagian. Dengan adanya alat ini diharapkan mampu membantu masyarakat dalam pengolahan buah pinang sehingga pekerjaan lebih ringan dan aman.

\section{METODE PENELITIAN}

Dalam penelitian ini langkah-langkah yang dilakukan akan disajikan dalam diagram alir pada Gambar 1 berikut ini:

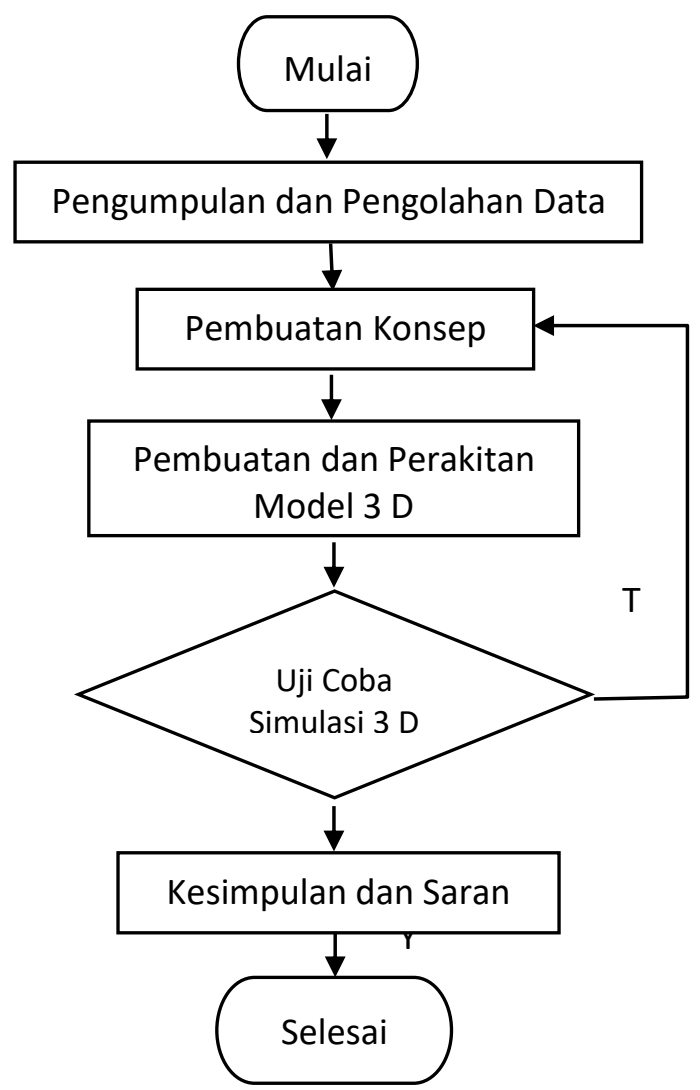

Gambar 1. Diagram Alir Tahapan Penelitian

\section{HASIL DAN PEMBAHASAN}

\subsection{Pengumpulan dan Pengolahan Data}

Pengumpulan dan pengolahan data dilakukan dengan beberapa metode, yaitu dengan studi pustaka, wawancara dan dokumentasi. Adapun untuk mempermudah dalam pembuatan mesin dilakukan percobaan secara langsung untuk mendapatkan gaya yang dibutuhkan untuk memotong satu buah pinang. Dalam percobaan ini peralatan yang digunakan seperti: timbangan, buah pinang dan pisau. 
Berdasarkan hasil penimbangan yang dilakukan diperoleh data sebagai berikut: dalam $1 \mathrm{~kg}$ buah pinang terdapat 18 buah, maka untuk mengetahui berat satu buah pinang dengan cara $1 \mathrm{~kg}$ dibagikan dengan 18 buah maka berat 1 buah pinang sebesar 0,056 kg / buah. Proses penimbangan buah pinang tersebut dapat dilihat pada gambar 2.

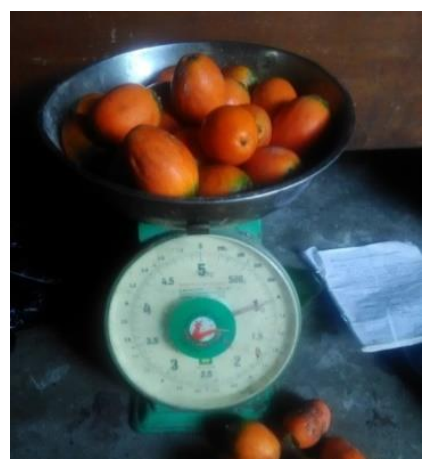

Gambar 2 Proses Penimbangan Berat Buah Pinang

Proses selanjutnya yaitu untuk menentukan berapa gaya yang diperlukan untuk pembelah buah pinang, prosesnya dapat dilihat pada Gambar 3.

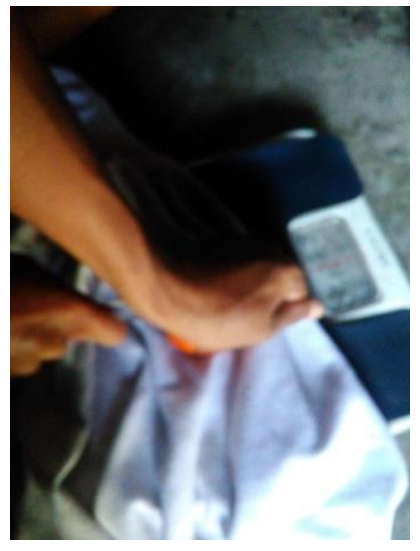

Gambar 3. Eksperimen Gaya Pembelahan Buah Pinang

Berdasarkan hasil uji coba yang dilakukan untuk mengetahui gaya pemotongan pada buah pinang yang dilakukan sebanyak lima kali diperoleh hasil yang dapat dilihat pada Tabel 1.

Tabel 1 Hasil Uji Coba Gaya Penekanan untuk Pembelah Buah Pinang

\begin{tabular}{|c|l|c|}
\hline No & Buah pinang & Gaya tekan $(\mathrm{kg})$ \\
\hline 1 & Uji coba pertama & 48 \\
\hline 2 & Uji coba kedua & 48 \\
\hline 3 & Uji coba ketiga & 47 \\
\hline 4 & Uji coba keempat & 50 \\
\hline 5 & Uji coba kelima & 48 \\
\hline
\end{tabular}

Berdasarkan hasil pengujian tersebut didapat gaya tekan yang diperlukan dalam membelah buah pinang adalah diambil gaya terbesar yaitu $50 \mathrm{~kg}$. 


\subsection{Pembuatan Konsep}

Pembuatan konsep dan perancangan mesin yang dilakukan dengan menganalisis konstruksi mesin yang akan dibuat sehingga dapat diperoleh alternatif beserta fungsinya yang akan dipilih berdasarkan target yang diinginkan tercapai sesuai dengan data-data yang diperoleh dari hasil pengumpulan data baik melalui buku-buku, referensi maupun pengamatan.

Dari data yang sudah terkumpul lalu diolah untuk dijadikan bahan referensi dalam proses pembuatan konsep mesin. Data-data yang menjadi pertimbangan dalam pembuatan konsep antara lain dapat dilihat pada tabel 2 .

Tabel 2. Tabel Daftar Kebutuhan

\begin{tabular}{ll}
\hline No. & \multicolumn{1}{c}{ Uraian } \\
\hline 1. & Dapat membelah dua bagian buah pinang \\
2. Kapasitas mesin $250 \mathrm{~kg} / \mathrm{jam}$ \\
3. Gaya pemotongan pisau $50 \mathrm{~kg}$ \\
\hline
\end{tabular}

Dari data-data tersebut diolah untuk dijadikan dasar dalam pembuatan konsep, konsep rancangan mesin dapat dilihat pada gambar 4.

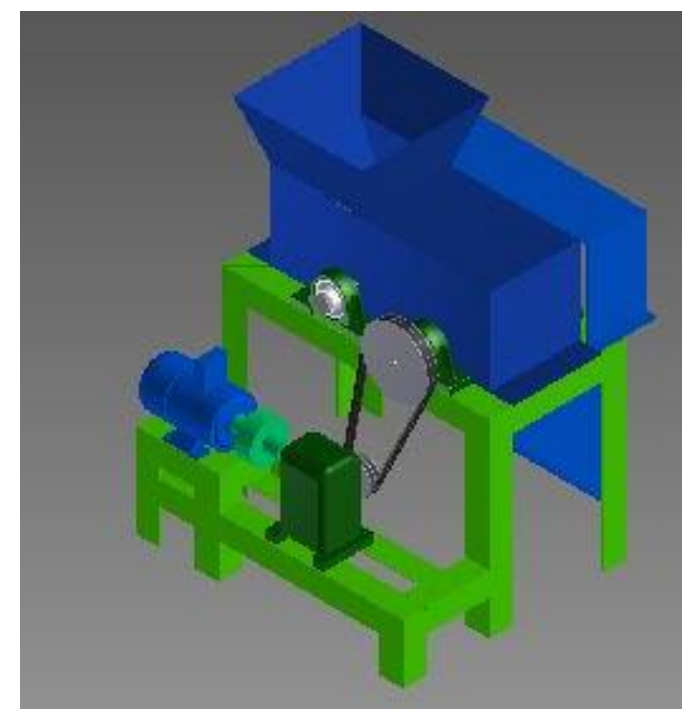

Gambar 4. Gambar Rancangan Konsep

\section{Cara Kerja Mesin}

Mesin ini terdiri dari beberapa bagian antara lain: bentuk hopper trapesium, sistem pembelahan menggunakan dua pembelah (pisau berputar vertikal), sistem tranmisi menggunakan kopling, pulley dan belt, dan roda gigi. Cara kerjanya adalah pada saklar on, motor listrik akan hidup dan berputar, kemudian putaran tersebut diteruskan oleh kopling masuk ke gearbox, setelah itu diteruskan lagi oleh pulley dan belt, kemudian diteruskan lagi oleh roda gigi. Berputaran pulley dan belt menyebabkan mata potong berputar, kemudian rotor pembawa berputar karena putaran pada roda gigi.

\subsection{Uji Coba}

Uji coba dilakukan setelah semua pembuatan dan perakitan model 3 dimensi berdasarkan rancangan konstruksi yang telah dianalisis dan dihitung sehingga mempunyai arah yang jelas dalam proses pemesinannya. Dari hasil pergerakan model 3d model pada mesin, didapat bahwa rancangan bergerak dengan baik. 


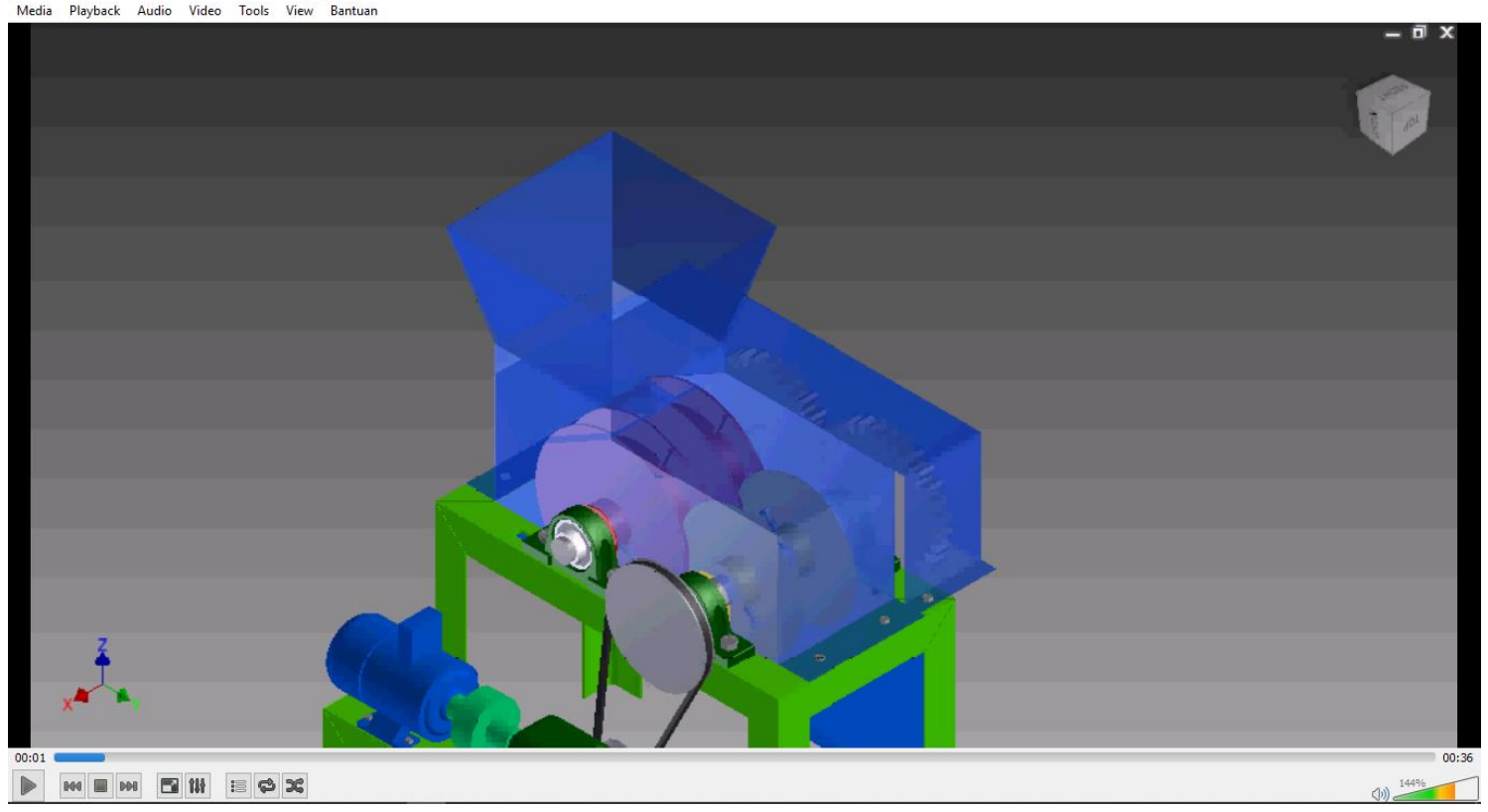

Gambar 5. Simulasi Pergerakan Model 3D

\section{SIMPULAN}

Berdasarkan pengujian kekuatan rancangan mesin pembelah buah pinang ini dengan bantuan software, mesin dapat memenuhi standar kekuatan. Dari hasil perhitungan yang dilakukan mesin dapat memenuhi tututan kapasitas $250 \mathrm{~kg} / \mathrm{jam}$ dan analisa fungsi bagian-bagian dari mesin dapat disimulasikan dengan baik.

\section{DAFTAR PUSTAKA}

[1]. Staples GW dan Bevacqua RF., Areca catechu (betel nut palm) Arecaceae (Arecoideae), Palm Family. ver. 1.3, Agustus 2006.

[2]. Barlina, R., Peluang Pemanfaatan Buah Pinang Untuk Pangan, Buletin Palma No.33, Desember 2007. 